Shin Kawana MD PhD, Junko Wachi MD, Masayasu Nakayama MD, Akiyoshi Namiki MD PhD

\title{
Comparison of haemodynamic changes induced by sevoflurane and halothane in paediatric patients
}

The purpose of this study is to investigate the haemodynamic effects of $1 \mathrm{MAC}$ and $2 \mathrm{MAC}$ of sevoflurane in children in comparison with halothane. Thirty-eight children (aged from one to six years, average age; $3.6 \pm 0.2 \mathrm{yr}$ ) were randomly assigned to four groups, depending on the dose and agent (1 and 2 MAC of sevoflurance: $S 1$ and S2; 1 and $2 M A C$ of halothane: $\mathrm{H1}$ and $\mathrm{H2}$, respectively). Afier collecting control data during $0.2 \mathrm{MAC}$ of either anaesthetic, end-expired anaesthetics were kept at 1 MAC or $2 M A C$ for 15 min. Mean blood pressure ( $m B P$ ) and stroke volume index (SVI), measured by impedance cardiometry, decreased in all groups without differences between groups. Heart rate (HR) increased in groups $S 1, S 2$ and $H 2$ but not in group H1. The HR in $S 2$ was higher than that in $H 2$. The cardiac index $(\mathrm{Cl})$, a product of $S V T$ and $H R$, tended to decrease but not significantly in all groups. These results suggested that the haemodynamic depressant effects of sevoflurane in children were similar to those of equipotent halothane concentration except for $H R$.

Cette étude vise à comparer, avec celles de lhalothane, les répercussions sur l'hémodynamique des enfants du sévoflurane à $M A C 1$ et 2. Trente-huit enfants (âgés de un à six ans, en moyenne 3,6 $\pm 0,2$ ans) sont répartis au hasard en quatre groupes, selon la concentration et l'agent (S1 et S2: sévoflurane $M A C 1$ et 2; HI et H2; halothane MAC I et 2 respectivement).

\section{Key words}

ANAESTHESIA: paediatric;

ANAESTHETICS, VOLATILE: sevoflurane, halothane;

MEASUREMENT TECHNIQUES: cardiac output, impedance cardiometry;

HEART: cardiac output, stroke volume.

From the Department of Anesthesiology, Sapporo Medical University School of Medicine, South 1, West 16, Chuo-ku, Sapporo, 060, Japan.

Address correspondence to: Dr. Shin Kawana, Department of Anesthesiology, Sapporo Medical University School of Medicine, South-1, West-16, Chuo-ku, Sapporo, 060, Japan. Accepted for publication 23rd March, 1995.
Après le recueil des données de contrôle pendant une anesthésie à MAC 0,2, la concentration téléexpiratoire de l'anesthésique est maintenue à $M A C 1$ or 2 pour 15 min. La pression artérielle moyenne (PAM) et l'index systolique (IS), mesuré par la cardiométrie par impédance, diminue dans tous les groupes et sans présenter de différences entre les groupes. La fréquence cardiaque (Fc) augmente dans les groupes S1, S2 et H2 mais pas dans le groupe HI. La Fc dans S2 est plus élevée que dans H2. Lindex cardiaque, le produit de IS et de Fc, tend à diminuer mais non significativement dans tous les groupes. Ces résultats suggèrent que les effets dépresseurs sur l'hémodynamique du sévoflurane chez les enfants sont identiques à ceux d'une concentration équivalente d'halothane.

Sevoflurane is used in paediatric anaesthesia ${ }^{1,2}$ because of its small blood-gas partition coefficient (0.63), ${ }^{3}$ which enables rapid induction of, and rapid emergence from anaesthesia. Paediatric patients have a relatively high minimum alveolar concentration (MAC) of volatile anaesthetics that may cause marked haemodynamic depression, especially in neonates and infants. ${ }^{4-7}$ In mongrel dogs, sevoflurane decreases cardiac output (CO) and mean blood pressure (mBP) without change in the heart rate (HR) ${ }^{8}$ The MAC of sevoflurane in children is much higher $(2.49 \%)^{2,9}$ than that in adults $(1.71-2.05 \%){ }^{10,11}$ However, there are no reports of haemodynamic effects of sevoflurane in paediatric patients receiving high concentrations of sevoflurane. The purpose of this study was to compare the haemodynamic effects of sevoflurane and halothane in paediatric patients by using impedance cardiometry, a noninvasive method to measure $\mathrm{CO}$ and stroke volume (SV).

\section{Methods}

After approval by the Ethics Committee of Sapporo Medical University, agreement was obtained from the parents of patients, to whom this study was fully explained. The investigation was carried out in 38 patients (from one to six years old) of ASA class I, who were to undergo 
surgery for strabismus or adenotonsilectomy. They were fasted overnight but were allowed free access to clear fluid until three hours before operation. They received premedication with a bromazepam 1.5 to $3 \mathrm{mg}$ suppository. On arrival in the operating room, their sedation was evaluated by a four grade score: (1) sleeping or sleepy, (2) sedated, (3) alert and (4) excited. Patients of grade 4 were excluded from the study. The remaining patients were randomly assigned to four groups, depending on the dose and agent (1.0 and 2.0 MAC of sevoflurane: $\mathrm{S} 1$ and S2; 1.0 and 2.0 MAC of halothane: $\mathrm{H} 1$ and $\mathrm{H} 2$, respectively). In this study, 1 MAC sevoflurane and halothane were defined as $2.49 \%{ }^{9}$ and $0.91 \%,{ }^{12}$ respectively. Anaesthesia was induced with oxygen $2 \mathrm{~L} \cdot \mathrm{min}^{-1}$, nitrous oxide $4 \mathrm{~L} \cdot \mathrm{min}^{-1}$ and 1 to $2 \mathrm{MAC}$ of sevoflurane or halothane, depending on the group. After an $\dot{w}$ catheter was placed and vecuronium $0.1 \mathrm{mg} \cdot \mathrm{kg}^{-1}$ was given $i v$, all anaesthetic agents were discontinued and the lungs were manually ventilated with $100 \%$ oxygen until the endexpired concentrations of sevoflurane or halothane were reduced to 0.2 MAC. End-expired anaesthetic agent and $\mathrm{CO}_{2}$ concentrations, sampled from the oral cavity at a rate of $200 \mathrm{ml} \cdot \mathrm{min}^{-1}$, were measured with an anaesthetic gas monitor (5250 RGM, Ohmeda Co. USA). The CO and SV were measured by impedance cardiometry (NCCOM 3, BoMed LTD, USA) and cardiac index (CI) and stroke volume index (SVI) were calculated. The $\mathrm{mBP}$, measured by the oscillometric method, and HR were monitored with a patient monitor (BP308E, Coline Co., Japan). The anaesthetic agent concentrations were then increased to $3 \%$ in group S1, 6\% in S2, $1.5 \%$ in $\mathrm{H} 1$ and $2.5 \%$ in $\mathrm{H} 2$ until the end-expired concentration reached the MAC assigned to the group. Thereafter, the inspiratory concentration was controlled to maintain the assigned end-expired concentrations until the end of the measurement. In the first several cases, measurement was continued for $20 \mathrm{~min}$. However, as no further haemodynamic changes were found after $15 \mathrm{~min}$, the measurement was terminated at $15 \mathrm{~min}$. The end-expired $\mathrm{CO}_{2}$ was controlled within 35 to $40 \mathrm{mmHg}$ through the measurment.

All results are expressed as mean \pm SEM. Data were analyzed by the Kruskal-Wallis test for patients' characteristics and by repeated-measure ANOVA for haemodynamic variables among groups. Dunnett's $t$ test was used to compare haemodynamic variables between control and measurement points. A $P$ value of less than 0.05 was considered statistically significant.

\section{Results}

There were no demographic differences among the groups (Table I). The end-expired $\mathrm{CO}_{2}$ and concentrations of anaesthetic agents were maintained within the assigned
TABLE I Demographic data

\begin{tabular}{llllll}
\hline & $\begin{array}{l}\text { Age } \\
(y r)\end{array}$ & $\begin{array}{l}\text { Body weight } \\
(\mathrm{kg})\end{array}$ & $\begin{array}{l}\text { Height } \\
(\mathrm{cm})\end{array}$ & $\begin{array}{l}\text { Sedation } \\
\text { score }\end{array}$ \\
\hline S1 & 9 & $4.0 \pm 0.3$ & $17.6 \pm 1.0$ & $102.8 \pm 1.6$ & 2 \\
S2 & 10 & $3.6 \pm 0.4$ & $16.5 \pm 1.2$ & $103.2 \pm 3.3$ & 2 \\
H1 & 9 & $3.7 \pm 0.4$ & $15.6 \pm 0.8$ & $96.0 \pm 2.7$ & 2 \\
H2 & 10 & $3.6 \pm 0.6$ & $15.6 \pm 1.1$ & $109.9 \pm 4.5$ & 2 \\
\hline
\end{tabular}

All results are expressed as mean \pm SEM except the sedation score which is presented as the mode. S1; 1 MAC sevoflurane, S2, 2 MAC sevoflurane, $\mathrm{H} 1 ; 1 \mathrm{MAC}$ halothane, $\mathrm{H} 2,2 \mathrm{MAC}$ halothane, $\mathrm{PETCO}_{2}$; end-expired $\mathrm{CO}_{2}$, $\mathrm{mBP}$; mean blood pressure, $\mathrm{HR}$; heart rate, $\mathrm{SVI}$; stroke volume index, $\mathrm{CI}$; candiac index.

ranges through the measurement. Control data of haemodynamic variables were shown in Table II.

The $\mathrm{mBP}$ decreased at the end of measurement in all groups $(P<0.05$ in $\mathrm{Sl}$ and $\mathrm{Hl}, P<0.01$ in $\mathrm{S} 2$ and $\mathrm{H} 2$ ). Changes in $\mathrm{mBP}$ were not different among the groups (Figure).

The SVI decreased at the end of measurement of all groups except group S1. The SVIs in the 2 MAC groups were lower than those in 1 MAC groups. (S1 vs $\mathrm{S} 2, \mathrm{H} 1$ vs $\mathrm{H} 2, P<0.01$ ) (Figure).

The HR increased in S1, S2 and H2, but not in H1. The HR at the end of measurement was higher in group $\mathrm{S} 2$ than in group $\mathrm{H} 2\left(135.3 \pm 4.2\right.$ beats $\cdot \mathrm{min}^{-1}$ in S2 vs. $114.4 \pm 4.8$ beats $\cdot \mathrm{min}^{-1}, P<0.01$ ) (Figure).

The CI, the product of SVI and HR, tended to decrease in all groups but not significantly and there were no differences among groups (Figure).

\section{Discussion}

The standard method of $\mathrm{CO}$ measurement in adults has been thermodilution, which is rarely applied to children without an absolute indication. In haemodynamic studies in chilldren or infants, echocardiography and Doppler ultrasound are widely used. ${ }^{4-6}$ Although these methods measure $\mathrm{CO}$ noninvasively, a skilled hand is necessary to obtain reproducible results because it is critical to avoid changing the position and direction of the probe during measurement. We used impedance cardiometry, which also measures SV and CO noninvasively. ${ }^{7,13-15}$ Two pairs of voltage-sensing electrodes and two pairs of current injection electrodes were attached to the lateral basis of the neck and the lateral thorax at the level of the xiphoid process. In adults, the $\mathrm{CO}$ thus obtained has a high correlation with that obtained by thermodilution. ${ }^{12}$ Although some bias was reported in measurement of $\mathrm{CO}$ and $\mathrm{SV}$ in paediatric patients, ${ }^{14}$ the control value of SVI in this study were 24.9 to $30.7 \mathrm{ml} \cdot \mathrm{m}^{-2}$, which corresponds to those obtained by echocardiography in previous reports. ${ }^{5}$ In addition, trends of SVI and CI measured 
TABLE II Control values of haemodynamic variables and $\mathrm{PETCO}_{2}$

\begin{tabular}{llllll}
\hline & $\mathrm{PETCO}_{2}(\%)$ & $\mathrm{mBP}(\mathrm{mmHg})$ & HR $\left(\right.$ beat $\left.\cdot \mathrm{min}^{-1}\right)$ & $S V I\left(\mathrm{ml} \cdot \mathrm{m}^{-2}\right)$ & $C I\left(\mathrm{~L} \cdot \mathrm{min}^{-1} \cdot \mathrm{m}^{-2}\right)$ \\
\hline S1 & $38.5 \pm 0.8$ & $74.9 \pm 0.9$ & $88.1 \pm 1.9$ & $29.6 \pm 2.0$ & $2.69 \pm 0.20$ \\
S2 & $35.3 \pm 2.5$ & $73.3 \pm 1.7$ & $95.4 \pm 4.6$ & $24.9 \pm 2.8$ & $2.44 \pm 0.20$ \\
H1 & $34.6 \pm 1.4$ & $73.1 \pm 1.7$ & $87.7 \pm 2.5$ & $30.7 \pm 2.0$ & $2.63 \pm 0.15$ \\
H2 & $37.5 \pm 2.8$ & $76.4 \pm 2.5$ & $99.7 \pm 3.4$ & $27.4 \pm 3.0$ & $2.77 \pm 0.4$ \\
\hline
\end{tabular}
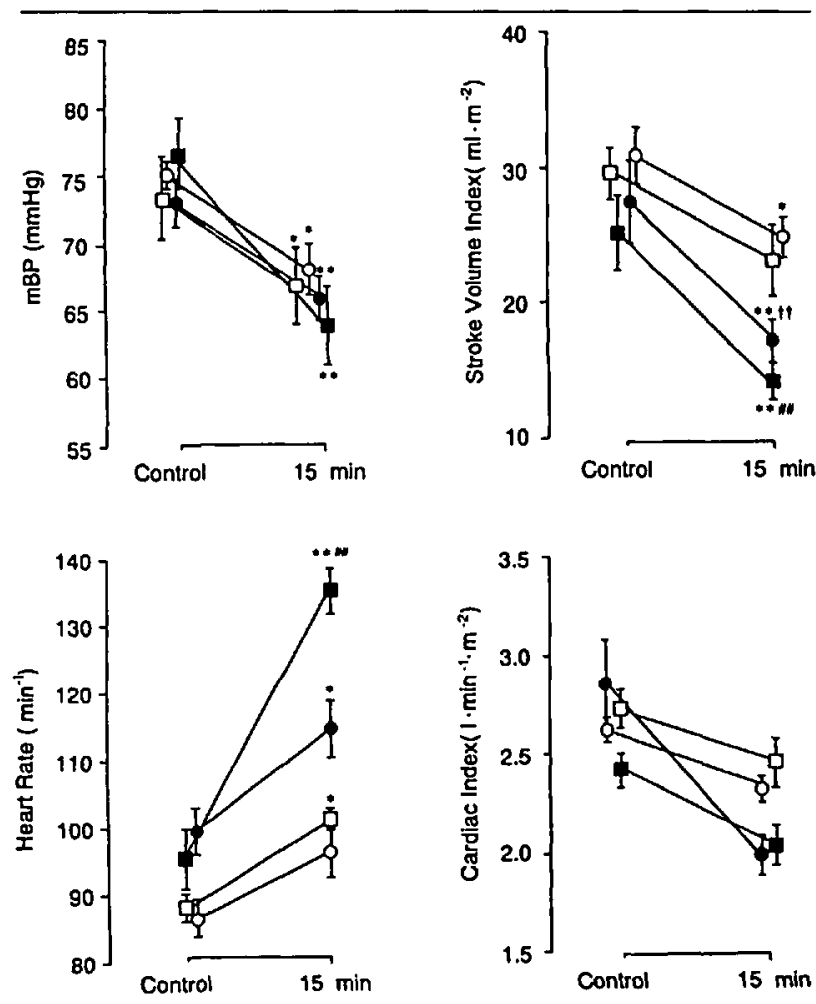

FIGURE Haemodynamic changes with sevoflurane and halothane. All results are presented as mean \pm SEM. Open squares; 1 MAC sevoflurane, closed squares; 2 MAC sevoflurane, open circles; 1 MAC halothane, closed circles; 2 MAC halothane; mBP; mean blood pressure, $\mathrm{HR}$; heart rate, SVI; stroke volume index, $\mathrm{CI}$; cardiac index. *, ** $P<0.05,0.01$ vs control, \#\#P<0.01 vs $1 \mathrm{MAC}$ sevoflurane, $\dagger P<0.01$ vs 1 MAC halothane.

by impedance cardiometry are clinically relevant because technical bias no longer occurs after starting measurement.

The results clearly showed that SVI was depressed with both sevoflurane and halothane in a dose-dependent fashion. The magnitude of the decrease in SVI with 1 MAC halothane corresponded to that in a previous report. ${ }^{5} \mathrm{Al}-$ though myocardial depression with halothane or isoflurane in infants and children has been investigated, ${ }^{3-7}$ the effects of sevoflurane on myocardial function has only been reported in adults and animal experiments. Kazama and $\mathrm{Ikeda}^{8}$ reported that left ventricular $\mathrm{dp} / \mathrm{dt} \max \mathrm{de}-$ creased as the sevoflurane concentration increased in mongrel dogs. Kikura and Ikeda ${ }^{16}$ also reported that sevoflurane/nitrous oxide depressed myocardial contractility in adults. Although preload changes were not evaluated, these results suggest that myocardial depression is predominant for the sevoflurane-induced decrease in SVI observed in this study.

The $\mathrm{HR}$ increased in all groups except $\mathrm{Hl}$ in a dosedependent fashion. The difference in HR between groups $\mathrm{S} 2$ and $\mathrm{H} 2$ was significant, while $\mathrm{mBP}$ decreased to a similar extent in both groups. Changes in HR with halothane were consistent with previous reports. ${ }^{4,5}$ Lerman et $a{ }^{2}{ }^{2}$ reported that 1 MAC sevoflurane increased HR moderately in children older than three years. Heart rate is influenced by many factors, such as preoperative condition, premedication and the induction method. There was no difference in the level of preoperative sedation among the groups (Table I). Bromazepam, used for premedication, is a benzodiazepine, ${ }^{17}$ which has little haemodynamic effect in the suppository dose of 1.5 to 3.0 $\mathrm{mg}$. The baroreflex, which is one of the mechanisms for increasing HR when BP is decreased, is attenuated by halothane. ${ }^{18,19}$ This may explain why HR increased only moderately despite decreases in $\mathrm{MBP}$ in the halothane groups. There are no reports of the effects of sevoflurane on the baroreflex. Thus, baroreflex preservation during sevoflurane anaesthesia may increase the $H R$ in response to decreasing blood pressure. Another possible mechanism increasing HR with sevoflurane is airway irritation. Among volatile anaesthetics, isoflurane and desflurane are reported to activate the sympathetic nervous system and consequently increase HR. ${ }^{21,21}$ Airway irritation is considered to be one of the mechanisms causing tachycardia. Although sevoflurane is less irritant, ${ }^{2}$ the high concentration used in this study may have increased HR through a mechanism similar to that of isoflurane or desflurane.

In the haemodynamic comparison of sevoflurane and halothane, HR was the only variable different between the groups. In the experiment with mongrel dogs, mBP, $\mathrm{CI}$, systemic vascular resistance and $\mathrm{dp} / \mathrm{dt}$ max decreased similarly in both agents up to 2 MAC. Halothane has little effects on vascular resistance in adults. ${ }^{22}$ Such an effect, however, was not confirmed in infants or children. 
It is difficult to evaluate directly changes in preload with both impedance and echocardiography. ${ }^{5}$ More precise investigation is necessary to clarify the difference in preload or vascular resistance among groups, if any.

The conditions under which control data are obtained are important in paediatric research. Although control data were often obtained before induction of anaesthesia, ${ }^{2,46}$ setting up the measurement equipment often makes children apprehensive and they become excited or cry. Thus, we measured control data during light anaesthesia. This could have resulted in underestimating the $\mathrm{mBP}, \mathrm{SVI}$ and $\mathrm{CI}$ changes. We did, however, observe changes in $\mathrm{mBP}$ and SVI. In contrast, changes in HR might be emphasized in comparison with previous reports. ${ }^{2,5} \mathrm{~A}$ recent report suggested that the MAC awake of sevoflurane is 0.3 in children, ${ }^{23}$ which is slightly higher than the MAC during our control data collection. However, no children complained of unpleasant experiences or remembered events during data collection.

In this study, we maintained a constant end-expired concentration for $15 \mathrm{~min}$, which allows sevoflurane to equilibrate in the brain. ${ }^{9}$ In addition, we observed that haemodynamic variables in some cases had already reached a stable state $15 \mathrm{~min}$ after induction even in the halothane groups. Thus, the results in this study were not different from those observed after long-term equilibration.

End-expired gas was sampled from the oral cavity to reduce entrained inspired gas. The lungs were manually ventilated at a slow rate $\left(\leq 20\right.$ breaths $\left.\cdot \mathrm{min}^{-1}\right)$ with a relatively large tidal volume. ${ }^{24}$ This manoeuvre prevented contamination by inspiratory gases, in which the agent concentrations were higher than in expired gas. Although sampling from a tracheal tube is more accurate, the trachea was not intubated to avoid haemodynamic changes during measurement.

In summary, the haemodynamic effects of $1 \mathrm{MAC}$ and 2 MAC of sevoflurane and halothane were investigated in 38 children. Both volatile anaesthetics decreased $\mathrm{mBP}$, SVI and increased HR in a dose-dependent fashion. The CI tended to decrease, but not significantly, in all groups. There were no differences in haemodynamic variables between the sevoflurane and halothane groups except in HR. The increase in HR in the 2 MAC sevoflurane groups was higher than that in the 2 MAC halothane group, resulting in attentuation of the decreased $\mathrm{CI}$.

\section{References}

1 Sarner JB, Levine M, Davis PJ, Lerman J, Cook DR, Motoyama EK. Clinical characteristics of sevoflurane in children. A comparison with halothane. Anesthesiology 1995; 82: 38-46.

2 Lerman J, Sikich $N$, Kleinman $S$, Yentis $S$. The pharma- cology of sevoflurane in infants and children. Anesthesiology 1994; 80: 814-24.

3 Strum DP, Eger EI II. Partition coefficients for sevoflurane in human blood, saline, and olive oil. Anesth Analg 1987; 66: 654-6.

4 Wolf $W J$, Neal MB, Peterson MD. The hemodynamic and cardiovascular effects of isoflurane and halothane anesthesia in children. Anesthesiology 1986; 64: 328-33.

5 Murray D, Vandewalker G, Matherne GP, Mahoney $L T$. Pulsed Doppler and two-dimensional echocardiography: comparison of halothane and isoflurane on cardiac function in infants and small children. Anesthesiology 1987; 67: 211-7.

6 Murray DJ, Forbes RB, Mahoney LT. Comparative hemodynamic depression of halothane versus isoflurane in neonates and infants: an echocardiographic study. Anesth Analg 1992; 74: 329-37.

7 Kawana S, Namiki A, Morita Y, Watanabe H, Tsuchida $H$. Hemodynamic responses during induction of anesthesia with halothane-nitrous oxide in children with or without atropine premedication. Journal of Anesthesia 1992; 6: 63-8.

8 Kazama T, Ikeda $K$. The comparative cardiovascular effects of sevoflurane with halothane and isoflurane. Journal of Anesthesia 1988; 2: 63-8.

9 Katoh T, Ikeda $K$. Minimum alveolar concentration of sevoflurane in children. Br J Anaesth 1992; 68: 139-41.

10 Katoh $T$, Ikeda $K$. The minimum alveolar concentration (MAC) of sevoflurane in humans. Anesthesiology 1987; 66: 301-3.

11 Scheller MS, Saidman LJ, Partridge BL. MAC of sevoflurane in humans and the New Zealand white rabbit. Can J Anaesth 1988; 35: 153-6.

12 Gregory GA, Eger EI II, Munson ES. The relationship between age and halothane requirement in man. Anesthesiology 1968; 30: 488-91.

13 Bernstein DP. A new stroke volume equation for thoracic electrical bioimpedance: theory and rationale. Crit Care Med 1986; 14: 904-9.

14 Salandin V, Zussa $C$, Risica G, et al. Comparison of cardiac output estimation by thoracic electrical bioimpedance, thermodilution, and Fick methods. Crit Care Med 1988; 16: 1157-8.

15 Introna RPS, Pruett JK, Crumrine RC, Cuadrado AR. Use of transthoracic bioimpedance to determine cardiac output in pediatric patients. Crit Care Med 1988; 16: 1101-5.

16 Kikura $M$, Ikeda $K$. Comparison of effects of sevoflurane/ nitrous oxide and enflurane/nitrous oxide on myocardial contractility in humans. Anesthesiology 1993; 79: 235-43.

17 Fukushima K, Sato T. Pharmacokinetics of bromazepam (suppository) in man. Masui 1980; 29: 1042-9.

18 Behnia $R$, Koushanpour $E$. Local versus central effect of 
halothane on carotid sinus baroreceptor function. Anesthesiology 1984; 61: 161-8.

19 Seagard JL, Hopp FA, Donegan JH, Kalbfleisch JH, Kampine JP. Halothane and the carotid sinus reflex: evidence for multiple sites of action. Anesthesiology 1982; 57: 191-202.

20 Yli-Hankala A, Randell T, Seppälä T, Lindgren L. Increases in hemodynamic variables and catecholamine levels after rapid increase in isoflurane concentration. Anesthesiology 1993; 78: 266-71.

21 Ebert TJ, Muzi M. Sympathetic hyperactivity during desflurane anesthesia in healthy volunteers: a comparison with isoflurane. Anesthesiology 1993; 79: 444-53.

22 Eger EI II, Smith NT, Stoelting RK, Cullen DJ, Kadis LB, Whitcher $C E$. Cardiovascular effects of halothane in man. Anesthesiology 1970; 32: 396-409.

23 Katoh T, Suguro Y, Ikeda T, Kazama T, Ikeda K. Influence of age on awakening concentrations of sevoflurane and isoflurane. Anesth Analg 1993; 76: 348-52.

24 Badgwell JM, Heavner JE, May WS, Goldthorn JF, Lerman J. End-tidal $\mathrm{P}_{\mathrm{CO}_{2}}$ monitoring in infants and children ventilated with either a partial rebreathing or a nonrebreathing circuit. Anesthesiology, 1987; 66: 405-10. 